\title{
Sex and Stature Estimation from Adult Lumbar Vertebrae in a Thai Population Based on Image Analysis
}

\author{
Estimación de Sexo y Estatura de Vértebras Lumbares Adultas \\ en una Población Tailandesa Basada en Análisis de Imagen
}

\author{
Nadthaganya Suwanlikhid ${ }^{1}$; Sukon Prasitwattanaseree ${ }^{2}$; Luciana La Tegola ${ }^{3}$; Patison Palee ${ }^{4}$; \\ Apichat Sinthubau ${ }^{1,5}$; Giuseppe Guglielmi ${ }^{3}$ \& Pasuk Mahakkanukrauh ${ }^{1,5,6}$
}

\begin{abstract}
SUWANLIKHID, N.; PRASITWATTANASEREE, S.; LA TEGOLA, L.; PALEE, P.; SINTHUBAU, A.; GUGLIELMI, G. \& MAHAKKANUKRAUH, P. Sex and stature estimation from adult lumbar vertebrae in a Thai population based on image analysis. Int. J. Morphol., 38(6):1651-1656, 2020.
\end{abstract}

SUMMARY: Although molecular techniques evolved considerably in last years, anthropological methods of assessing skeletal remains, continues to be an important tool in the identification process in medico legal investigations. The objective of this study was to develop a discriminant function equation for estimating sex and stature using several measurements of lumbar vertebrae in a Thai population. We studied 150 lumbar columns ( 75 male and 75 female) age range of 22 to 89 years from the Forensic Osteology Research Center, Chiang Mai University, Thailand. The quantitative variables with sex were analyzed by the discriminant function analysis and that with stature were calculated using linear regression. The pixel density of the major axis of the trabecular surface of superior endplate of the first lumbar vertebra had the most accuracy in sex determination. The regression equation with quantitative variables in stature estimation described $32.3 \%$ of the total variance with standard error of estimate of $7.736 \mathrm{~cm}$. Lumbar vertebrae can be used as part of the stature and sex quantitatively and qualitatively estimating in Thais incomplete skeletal remains.

KEY WORDS: Forensic science; Image analysis; Lumbar vertebrae; Sex estimation; Stature estimation; Thai.

\section{INTRODUCTION}

Determining sex and stature is an important issue in anthropological, forensic and natural disasters. These are some of the indicators for detecting skeletal remains that play an important role in a biological profile.

Image processing is a new approach to quantitatively extract and analyze different bone images (Liu et al., 1995). It provides more reliable data and relates bone characteristics to sex and stature. In previous studies, the lumbar vertebrae determined the estimate of sex and stature with metric analysis (Sintubua \& Mahakkanukrauh, 2001; Ostrofsky \& Churchill, 2015). Therefore, a better method is needed to make non-invasive automated computer technology easy to use, saving time and to share data with other experts.
Some studies have focused on microscopic structures of bones such as the femur, tibia, fibula, iliac crest of the hip in cross-sectional images for age-related bone diseases (Liu et al., 1996; Jatti, 2012) using image processing techniques. Other reports have studied cervical and lumbar vertebrae for estimating sex (Badr EI Dine \& El Shafei, 2015; Oura et al., 2018) and stature (Klein et al., 2015; Zhang et al., 2015) in CT and MRI. However, there are no studies on coarse bone anatomy with estimation of sex and stature by image analysis.

The lumbar vertebrae are the largest segments of the spinal columns. They support the load of the body, promote movement and are extremely flexible (Drake et al., 2015).

\footnotetext{
${ }^{1}$ Forensic Osteology Research Center, Faculty of Medicine and Graduate School, Chiang Mai University, Chiang Mai, Thailand.

${ }^{2}$ Department of Statistics, Faculty of Science, Chiang Mai University, Chiang Mai, Thailand.

${ }^{3}$ Department of Clinical and Experimental Medicine, Foggia University School of Medicine, Viale Luigi Pinto 1, Foggia, 71120, Italy.

${ }^{4}$ College of Arts, Media and Technology, Chiang Mai University, Chiang Mai, Thailand.

${ }^{5}$ Department of Anatomy, Faculty of Medicine, Chiang Mai University, Chiang Mai, Thailand.

${ }^{6}$ Excellence Center in Osteology Research and Training Center (ORTC), Chiang Mai University, Chiang Mai, Thailand.

This study was funded in part by Faculty of Medicine, Chiang Mai University, grant number 2560-04678.
} 
SUWANLIKHID, N.; PRASITWATTANASEREe, S.; LA TEgOla, L.; PALEE, P.; SiNTHUBAU, A.; GUGLIELMI, G. \& MAHAKKANUKRAUH, P. Sex and stature estimation from adult lumbar vertebrae in a Thai population based on image analysis. Int. J. Morphol., 38(6):1651-1656, 2020.

In males they are likely to be larger than in females because of weight-bearing transmitting from the upper body to pelvis (Krogman \& Iscan, 1986). Furthermore, the height of one or two vertebrae can be related to the stature (Tibbetts, 1981) considering that the vertebral column is the main component (Bogin \& Varela-Silva, 2010).

In 53 recovered human remains, skulls were found in about $80-100 \%$ and pelvis, femur and vertebrae, in about 60 $79 \%$ (Sorg \& Haglund, 1996). However, the body of the lumbar vertebrae is often better preserved than long bones, because they can remain intact after sustaining severe burns thanks to the covering of soft tissues (Nagesh \& Kumar, 2006).

Computer technology is developing rapidly to make it available to the medical public. Therefore, in this research we will present an image analysis for the qualitative and quantitative program of bone images in successful semiautomated applications. Furthermore, there is no estimate of sex and stature in the lumbar vertebrae using imaging technique. The objective of this study was to develop an equation for estimating sex and stature in a Thai population by our image analysis software.

\section{MATERIAL AND METHOD}

A total of 150 dry bones, including 75 Thai males and 75 females, of lumbar vertebrae between the ages of 21 and 90 were collected by the Forensic Osteology Research Center (FORC), Faculty of Medicine, Chiang Mai University. The exclusion criteria were damage, fractures, trauma or pathological spine.

In this application, we were interested in the segmentation of bone images related to the estimate of sex and stature. The following nine parameters were measured by area, major and minor axis in total area, cortical and trabecular area in each lumbar vertebra (Table I).

The lumbar vertebrae in the vertical plane were photographed on upper and lower plates using the Sony camera and set with an aperture priority of $\mathrm{f} / 20$, shutter speed
1/10 and International Organization for Standardization (ISO) 400. They were positioned parallel to the camera, resting on a mobile steel platform with ruler at $260 \mathrm{~mm}$ from the camera with white light. All were covered by a black photo booth. Bone images were minimized by an image resizing program because it helped to evaluate quickly. Then, we insert a new bone image into the Paint program to find the number of pixels per $1 \mathrm{~cm}$ and we insert it into the image analysis software program. Image analysis is an image processing using mathematical operations in which the input is the image such as photography, the output is a quantitative output from the functionalities. Digital image processing techniques help manipulate digital images using computers (Acharya \& Ray, 2005).

The four steps of the digital image processing technique are pre-processing, segmentation, post processing and feature extraction.

- in the preprocessing there is removal of artifacts and degradations to obtain reliable and accurate information.

- in the segmentation there is analysis of important agerelated bone characteristics, including the area, major axis and minor axis (Liu et al., 1995).

- post processing is a phase of improvement of the over segmentation and sub-segmentation.

- Features extraction is a numerical extract from segmented areas that can be used in statistical analysis.

The PMT (Porosity Measurement Tool) was used to analyze red, green and blue (RGB) images with finding the marked boundary about 40 points on the external surface of the cortical and trabecular bone of the lumbar vertebrae. Then, we right-clicked to create a mask on the marking one on the external surface of the cortical and trabecular bone of the lumbar vertebrae to analyze nine quantitative variables (Fig. 1) on areas of the total, cortical and trabecular surface in both the upper and lower plates. Subsequently, the image processing program had identified only the quantitative variables on areas of the total, cortical and trabecular bone (Figs. 2 and 3). Finally, the quantitative variables were extracted from the area pixel density, major and minor axis in total surface, cortical surface and trabecular surface of both the upper and lower end plates in each lumbar vertebra.

Table I. Definitions of quantitative variables.

\begin{tabular}{ll}
\hline & \multicolumn{1}{c}{ Definition } \\
\hline Area & The area of total surface (AA), cortical (AC) and trabecular surface (AT). \\
Major axis & The longest axis passes through the total surface (MAA), cortical (MAC) and \\
& trabecular surface (MAT). \\
Minor axis & The shortest axis passes through perpendicular to the major axis at the center \\
& from one side of total surface (MIA), cortical (MIC) and trabecular surface \\
& (MIT) to the other.
\end{tabular}




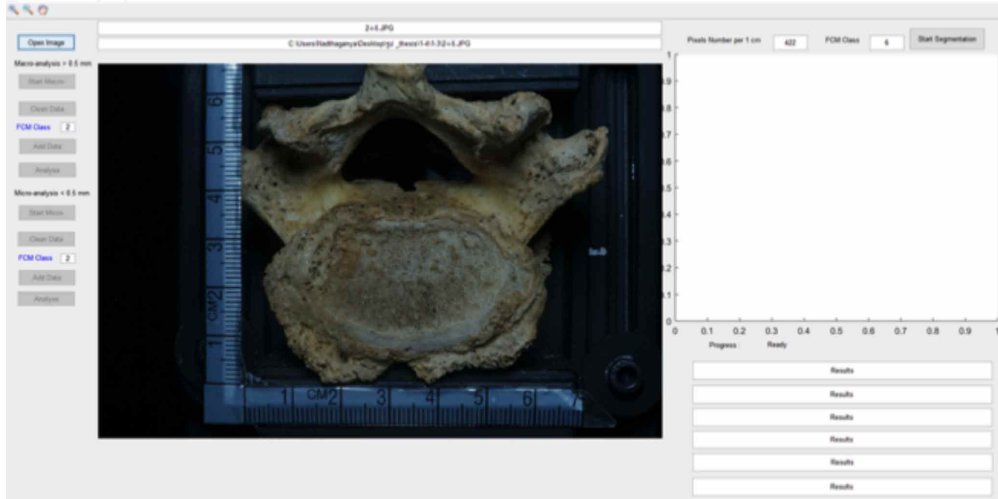

Fig. 1. The bone image and table for showing the pixel density of quantitative variables in the image analysis software program.

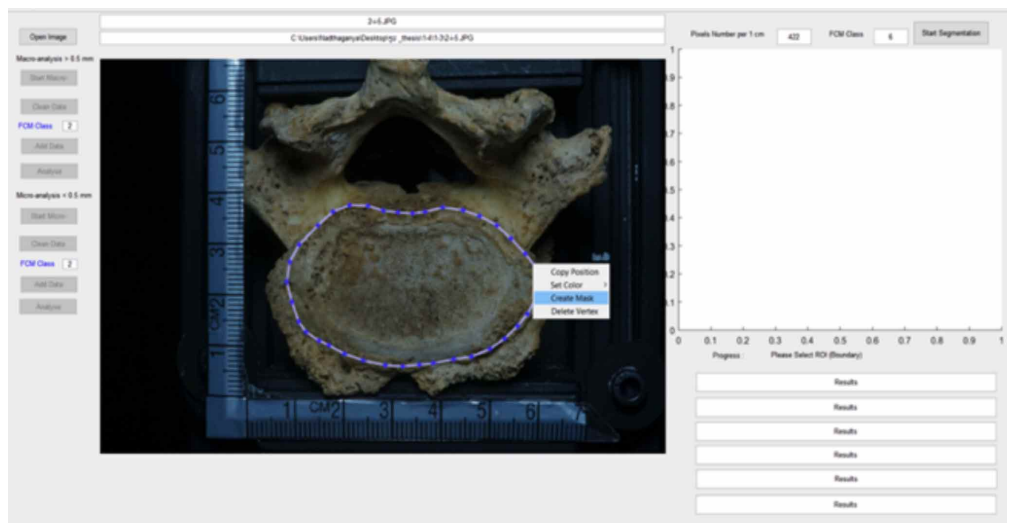

Fig. 2. Marking boundary and clicking one point of boundary to create mask on the outer surface of cortical bone.

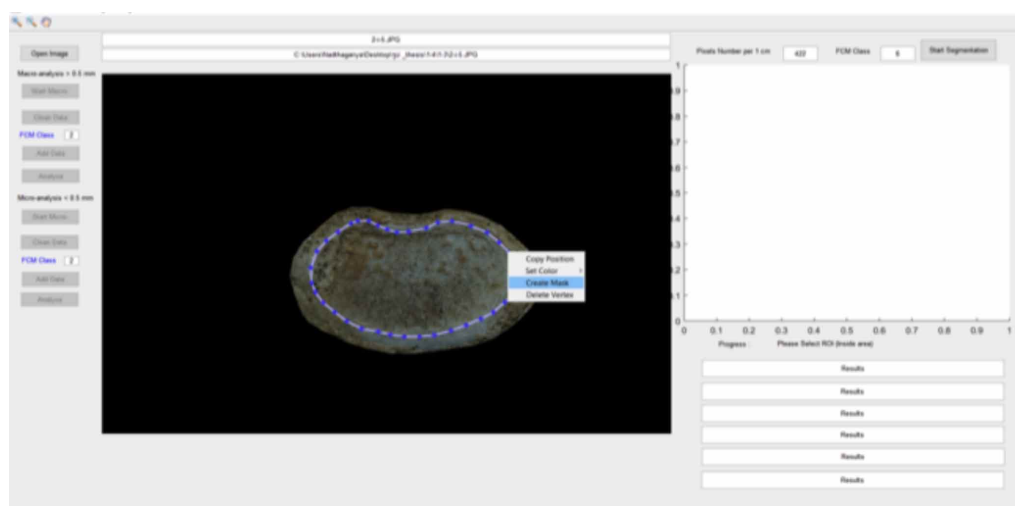

Fig. 3. Marking boundary and clicking one point of boundary to create mask on the outer surface of trabecular bone.

Statistical analysis was performed with the statistical package for the Social Sciences Software Package (SPSS, version 20). Quantitative variables and sex were calculated using the gradual method of discriminant function analysis. A simple linear regression model was developed by selecting the quantitative variables that contributed significantly to the stature estimate. The significance threshold was established at $\mathrm{p}<0.01$.

\section{RESULTS}

The mean age of males was $59.44 \pm$ 17.14 (mean \pm SD) years and females $59.67 \pm$ 16.29 (mean \pm SD) years. The average stature of males was $165.75 \pm 7.257$ (mean $\pm \mathrm{SD}$ ) $\mathrm{cm}$ and females was $154.07 \pm 7.522$ (mean $\pm \mathrm{SD}$ ) $\mathrm{cm}$. There were significant differences $(\mathrm{p}$ $<0.01$ ) between the sexes in most parameters except $\mathrm{AC}$ on the lower end plate of the $\mathrm{L} 1$ to $\mathrm{L} 3$ vertebra and $\mathrm{AC}$ on the upper and lower end plate of the L4 to L5 vertebra. In general, most of the quantitative variables were greater in males than in females.

The accuracy of the sex estimate with the univariate equations ranged from $57.4 \%$ to $81.8 \%$ and two quantitative variables (MAT and $\mathrm{AA}$ ) on the upper end plate of the L1 vertebra had an accuracy greater than $80 \%$. The accuracy rates for the analysis ofunivariate discriminant function ranged from $59.5 \%$ to $81.8 \%$ for the $\mathrm{L} 1$ vertebra. The best precision of the quantitative variable on the upper end plate and on the lower end plate of the L1 vertebra were MAT and MIA respectively.

Accuracy rates for univariate discriminant function analysis ranged from $59.5 \%$ to $77.7 \%$ for the L2 vertebra. The best accuracy of the quantitative variable on the upper end plate and the lower end plate of the L2 vertebra was AA.

Accuracy rates for the analysis of univariate discriminant function ranged from $58.1 \%$ to $75 \%$ for the L3 vertebra. The best accuracy of the quantitative variable on the upper and lower end plate of the L3 vertebra was AC.

Accuracy rates for univariate discriminant function analysis ranged from $60.4 \%$ to $76.5 \%$ for the L4 vertebra. The best accuracy of the quantitative variable on the upper and lower end plate of the L4 vertebra were $\mathrm{AC}$ and $\mathrm{AA}$ respectively.

Accuracy rates for univariate discriminant function analysis ranged from $57.6 \%$ to 75.3 $\%$ for the L5 vertebra. The best accuracy of the quantitative variable on the upper and lower end plates of the L5 vertebra were MIT and AA respectively. 
There was no qualified qualitative variable for analysis in TA on the lower end plates of the L1, L2 and L4 vertebrae and on the upper and lower end plates of the L5 vertebra.

A simple linear regression equation with quantitative variables in estimating stature had a range of the coefficient of determination (R2) between 0.114 and 0.323 with the standard errors of estimates (SEE) between 7.736 and $8.815 \mathrm{~cm}$ for the vertebra L1. The best R2 with SEE of quantitative variable on the upper end plate and the lower end plate of the $\mathrm{L} 1$ vertebra were AA and MIA respectively.

The quantitative variables in estimating the stature had an $\mathrm{R} 2$ range between 0.116 and 0.310 with SEE between 7.855 and $8.891 \mathrm{~cm}$ for the L2 vertebra. The best R2 with SEE of quantitative variable on the upper end plate and the lower end plate of the L2 vertebra were AA and MIA respectively.

The quantitative variables in estimating stature had an R2 range of 0.048 to 0.332 with SEE between 7.699 to $9.226 \mathrm{~cm}$ for the L3 vertebra. The best R2 with SEE of quantitative variable on the upper end plate and the lower end plate of the L3 vertebra were the MIC and the AA respectively.

The quantitative variables in estimating the stature had an R2 interval between 0.030 and 0.267 with SEE between 8.096 and $9.313 \mathrm{~cm}$ for the L4 vertebra. The best R2 with quantitative variable SEE on the upper end plate and the lower end plate of the L4 vertebra were the MIC and MIA respectively.

The quantitative variables in estimating the stature had an R2 interval between 0.070 and 0.250 with SEE between 7.900 to $8.843 \mathrm{~cm}$ for the L5 vertebra. The best R2 with quantitative variable SEE on the upper end plate and the lower end plate of the L5 vertebra was MIA.

\section{DISCUSSION}

For the estimation of sex, most of the area in each of the lumbar vertebrae is more accurate than other quantitative variables and most of the female is more accurate than the male. In our study, the upper end plate MAT of the L1 vertebra had the most predictive precision $(81.8 \%)$. Most of the upper lumbar vertebrae had higher precision than the upper lumbar vertebrae which agree with the study of Ostrofsky \& Churchill. Furthermore, there were no significant differences $(\mathrm{P}<0.01)$ between sex in the $\mathrm{AC}$ on the lower end plates of the vertebrae $\mathrm{L} 1$ to $\mathrm{L} 3$ and the $\mathrm{AC}$ on the upper and lower end plates of the vertebrae L4 to L5. This may be less dimorphic in the lower lumbar region and the lower vertebral body becomes flatter to increase stabilization and load so that width and length were greater than height (Masharawi et al., 2008).

The univariate of the discriminant function coefficients found that the MAT was the best predictive variable. The equations can be applied in complete compact bone and complete trabecular bone. In addition, the upper lumbar vertebrae had better accuracy than the lower lumbar vertebrae.

Various research has been reported on the determination of sex.

Our study showed greater precision than the previous study by Sintubua \& Mahakkanukrauh which reported in the northern Thai population the horizontal and anteroposterior diameter of the vertebral bodies more suitable for sex determination. In the present study, the accuracy of sex in the analysis of univariate function was similar to the study by Ostrofsky \& Churchill. The study by Badr El Dine \& El Shafei on the L1 vertebra obtained a lower precision (68\%) than Zheng et al. (2012), it could be due to the number of measurements and the difference in the sample size. Therefore, they suggested using more cases with multiple age groups and focusing on the L2-L5 vertebrae; our study followed all these tips. The study by Oura et al. (2018) had an accuracy greater than $80 \%$ in the L4 vertebra while our study had a lower accuracy. The difference in the results may be due to the sample size, population variability as ancestral, geographic, method and measurement. Furthermore, sexual dimorphism depends on genetics, race, diseases, socioeconomic status and nutrition (Mall et al., 2001). Furthermore, the different methodological approaches could explain the different accuracy (Yu et al., 2008).

For the estimate of stature, the total variance of the quantitative variable showed that most of the lumbar spine at the upper levels, had a better determination coefficient with the standard errors of the estimates than at the lower levels.

The determination coefficient with the smallest of the standard estimate error was the AA on the upper end plate on the L1 vertebra. The previous study of Mahakkanukrauh et al. (2011), on long bone in Thailand had the lowest standard estimate error $(\mathrm{SEE}=4.89 \mathrm{~cm})$ in the fibula among males and $(\mathrm{SEE}=5.21 \mathrm{~cm})$ in the femur, while our study had a higher error than standard estimates. However, the lumbar vertebrae can be helpful in estimating stature if long bones are inaccessible or missing. 
Equations for estimating stature can be used for complete compact bone and trabecular bone.

Among the previous studies, Tibbetts on measuring the height of individual vertebral bodies, described the standard errors of the estimates from 5.309 to $6.633 \mathrm{~cm}$. The study by Terazawa et al. (1990) measured the length of the lumbar spine during the autopsy using a steel measurement from the upper edge of the first lumbar vertebral body, along the front surface of the spine. The standard errors of estimates were $6.16 \mathrm{~cm}$ in males and $4.05 \mathrm{~cm}$ in females with better standard estimate errors than in the Tibbetts study (Tibbetts). Nagesh \& Kumar measured the average portion of the intervertebral discs from the point between T12 and L1 to the point between L5 and S1. The standard errors of the estimates were 4.38 to $5.65 \mathrm{~cm}$ in males and $4.16-5.58 \mathrm{~cm}$ in females. Zhang et al. measured the anterior, posterior and central heights of each lumbar vertebral body. The standard errors of the estimates were 4,108 to $6,010 \mathrm{~cm}$ in males and 2,982 to $4,912 \mathrm{~cm}$ in females.

The genetic and environmental factors derived for different inherent population groups lead to different equations (Kanchan et al., 2008). Klein et al. studied each vertebra (from L2 to L5) with three-dimensional (3D) reconstruction. The largest correlation with a single vertebral measurement was obtained in the central vertebral body height of L2 with standard estimate errors of $5.9 \mathrm{~cm}$. Oura et al. (2008) measured the maximum and minimum widths, depths and heights of the body L4. Vertebral depth and width $(\mathrm{r}=0.703$ to 0.711$)$ had a stronger correlation with stature $(\mathrm{r}$ $=0.529$ ) than vertebral height. Therefore, the vertebral dimension seems to estimate the stature more precisely of the vertebral height. For both sexes, the standard error of the estimate was $5.635 \mathrm{~cm}$ in multiple linear regression.

The results of our study found that the standard errors of the estimates differ from previous studies. It could be the quantitative variables, the method in the statistics and the sample size. However, it is a new method for estimating stature to use easily and qualitatively.

The image analysis software program in this research is appropriate in law and forensic science. However, a limitation in this study must be identified in the correct lumbar level and in the absence of quantitative variables, for assessing the sex and stature they expect to explore using image analysis in a Thai population.

Previous research and analysis of the bone image have processed a small number of bone samples (Klein et al.). Therefore, it is essential to develop a large number of bone specimens for consistent results. This document provided a larger sample size than previous research on image analysis that supports the results.

Our findings add to the growing evidence that vertebrae can be used accurately, as part of the sexual process.

It can be applied in incomplete bone to estimate the sex and stature of the individual lumbar vertebral body; it is suitable for assessing sex and stature in decomposed or severely burnt bodies when the pelvis, skull and long bones are poorly preserved or unavailable. Moreover, it can be considered of use in traditional methods of sexuality and stature. Another strength of this study is that image analysis generates quantitative analysis by sex and stature estimate with a method comparable to other methods and provides consistent results. We further develop and improve the accuracy of an automated system in a segmented process for bone image characteristics to obtain more reliable information for estimating sex and height. This could be widely used for remote consultation within a Thai population.

Further studies are needed to study whether the application of these simple parameters to other lumbar and spinal segments, can produce equally important results. whether the combination of vertebral dimensions from different spinal segments can increase the accuracy of the sex estimate; and which factors affect lower accuracy of estimate of sex among men.

\section{ETHICALSTANDARDS AND INFORMED CONSENT}

All procedures followed were in accordance with the ethical standards of the responsible committee on human experimentation (institutional and national) and with the Helsinki Declaration of 1975, as revised in 2000.

SUWANLIKHID, N.; PRASITWATTANASEREE, S.; LA TEGOLA, L.; PALEE, P.; SINTHUBAU, A.; GUGLIELMI, G. \& MAHAKKANUKRAUH, P. Estimación de sexo y estatura de vértebras lumbares adultas en una población tailandesa basada en análisis de imágenes. Int. J. Morphol., 38(6):1651-1656, 2020.

RESUMEN: Los métodos antropológicos de evaluación del esqueleto siguen siendo una herramienta importante en el proceso de identificación en las investigaciones médico-legales. El objetivo de este estudio fue desarrollar una ecuación de función discriminante para estimar el sexo y la estatura utilizando varias medidas de las vértebras lumbares en una población tailandesa. Se estudiaron 150 columnas lumbares ( 75 hombres y 75 mujeres) con un rango etario de 22 a 89 años del Centro de Investigación de Osteología Forense, Universidad de Chiang Mai, Tailandia. Las variables cuantitativas de sexo se analizaron mediante el análisis de función discriminante y la estatura fue calculada mediante regresión lineal. En cuanto a la determinación de sexo, la densidad 
de píxeles del eje mayor de superficie trabecular de la placa terminal superior de la primera vértebra lumbar fue de mayor precisión. La ecuación de regresión con variables cuantitativas en la estimación de la estatura describió el $32,3 \%$ de la varianza total con el error estándar de estimación de $7,736 \mathrm{~cm}$. Las vértebras lumbares se pueden utilizar como parte de la estatura y el sexo, estimando cuantitativa y cualitativamente los restos esqueléticos incompletos en sujetos tailandeses.

PALABRAS CLAVE: Ciencia forense; Análisis de imagen; Vértebra lumbar; Estimación del sexo; Estimación de la estatura; Tailandés.

\section{REFERENCES}

Acharya, T. \& Ray, A. K. Image Processing. Principles and Applications. Hoboken, John Wiley, 2005.

Badr El Dine, F. M. M. \& El Shafei, M. M. Sex determination using anthropometric measurements from multi-slice computed tomography of the 12th thoracic and the first lumbar vertebrae among adult Egyptians. Egypt. J. Forensic Sci., 5(3):82-9, 2015.

Bogin, B. \& Varela-Silva, M. I. Leg length, body proportion, and health: a review with a note on beauty. Int. J. Environ. Res. Public Health, 7(3):1047-75, 2010.

Drake, R. L.; Vogl, W. \& Mitchell, A. W. M. Gray's Anatomy For Students. 3rd ed. Edinburgh, Churchill Livingstone, 2015.

Jatti, A. Segmentation of microscopic bone images. Int. J. Electron. Eng., 2(1):11-5, 2012.

Kanchan, T.; Menezes, R. G. \& Kotian, M. S. Stature estimation: valuable precautions. J. Forensic Leg. Med., 15(6):413, 2008.

Klein, A.; Nagel, K.; Gührs, J.; Poodendaen, C.; Püschel, K.; Morlock, M. M: \& Huber, G. On the relationship between stature and anthropometric measurements of lumbar vertebrae. Sci. Justice, 55(6):383-7, 2015.

Krogman, W. M. \& Iscan, M. Y. The human skeleton in forensic medicine. Springfield (IL), Charles C. Thomas, 1986.

Liu, Z. Q.; Austin, T. J. \& Moore, D. Image Processing Techniques for Bone Image Analysis. Washington (DC), Proceedings of the 1995 International Conference on Image Processing, 1995. pp.458-61.

Liu, Z. Q.; Austin, T.; Thomas, C. D. L. \& Clement, J. G. Bone feature analysis using image processing techniques. Comput. Biol. Med., 26(1):65-76, 1996.

Mahakkanukrauh, P.; Khanpetch, P.; Prasitwattanseree, S.; Vichairat, K. \& Case, D. T. Stature estimation from long bone lengths in a Thai population. Forensic Sci. Int., 210(1-3):279.e1-7, 2011.

Mall, G.; Hubig, M.; Büttner, A.; Kuznik, J.; Penning, R. \& Graw, M. Sex determination and estimation of stature from the long bones of the arm. Forensic Sci. Int., 117(1-2):23-30, 2001.

Masharawi, Y.; Salame, K.; Mirovsky, Y.; Peleg, S.; Dar, G.; Steinberg, N. \& Hershkovitz, I. Vertebral body shape variation in the thoracic and lumbar spine: characterization of its asymmetry and wedging. Clin. Anat., 21(1):46-54, 2008

Nagesh, K. R. \& Kumar, G. P. Estimation of stature from vertebral column length in South Indians. Leg. Med., 8(5):269-72, 2006.

Ostrofsky, K. R. \& Churchill, S. E. Sex determination by discriminant function analysis of lumbar vertebrae. J. Forensic Sci., 60(1):21-8, 2015.

Oura, P.; Karppinen, J.; Niinimäki, J. \& Junno, J. A. Sex estimation from dimensions of the fourth lumbar vertebra in Northern Finns of 20, 30, and 46 years of age. Forensic Sci. Int., 290:350.e1-350.e6, 2018

Oura, P.; Korpinen, N.; Niinimäki, J.; Karppinen, J.; Niskanen, M. \& Junno, J.A. Estimation of stature from dimensions of the fourth lumbar vertebra in contemporary middle-aged Finns. Forensic Sci. Int., 292:71-7, 2018.
Sintubua, A. \& Mahakkanukrauh, P. Thai sexing and vertebral column. Bull. Chiang Mai Assoc. Med. Sci., 34(1):22-30, 2001.

Sorg, M. H. \& Haglund, W. D. Forensic Taphonomy: The Postmortem Fate of Human Remains. Boca Raton, CRC Press, 1996.

Terazawa, K.; Akabane, H.; Gotouda, H.; Mizukami, K.; Nagao, M. \& Takatori, T. Estimating stature from the length of the lumbar part of the spine in Japanese. Med. Sci. Law, 30(4):354-7, 1990.

Tibbetts, G. L. Estimation of stature from the vertebral column in American Blacks. J. Forensic Sci., 26(4):715-23, 1981.

Yu, S. B.; Lee, U. Y.; Kwak, D. S.; Ahn, Y. W.; Jin, C. Z.; Zhao, J.; Sui, H. J. \& Han, S. H. Determination of sex for the 12th thoracic vertebra by morphometry of three-dimensional reconstructed vertebral models. $J$. Forensic Sci., 53(3):620-5, 2008.

Zhang, K.; Chang, Y. F.; Fan, F. \& Deng, Z. H. Estimation of stature from radiologic anthropometry of the lumbar vertebral dimensions in Chinese. Leg. Med. (Tokyo), 17(6):483-8, 2015.

Zheng, W. X.; Cheng, F. B.; Cheng, K. L.; Tian, Y.; Zhang, W. S.; Zheng, Y. J. \& Li, Y. Q. Sex assessment using measurements of the first lumbar vertebra. Forensic Sci. Int., 219(1-3):285.e1-5, 2012.

Corresponding author:

Giuseppe Guglielmi, MD

Professor of Radiology

Department of Clinical and Experimental Medicine

University of Foggia

Viale L. Pinto 1

71120 Foggia

ITALY

Email: giuseppe.guglielmi@unifg.it

Received: 16-06-2020

Accepted: 24-07-2020 